\title{
Identification of Phytoconstituents as Potent Inhibitors of Casein Kinase-1 Alpha Using Virtual Screening and Molecular Dynamics Simulations
}

\author{
Alaa Shafie ${ }^{1}$, Shama Khan ${ }^{2}$, Zehra ${ }^{3}$, Taj Mohammad ${ }^{4}{ }^{\mathbb{D}}$, Farah Anjum ${ }^{1}$, Gulam Mustafa Hasan ${ }^{5}$, \\ Dharmendra Kumar Yadav $6, *($ ) and Md. Imtaiyaz Hassan $4, *$ (i)
}

check for updates

Citation: Shafie, A.; Khan, S.; Zehra; Mohammad, T.; Anjum, F.; Hasan, G.M.; Yadav, D.K.; Hassan, M.I. Identification of Phytoconstituents as Potent Inhibitors of Casein Kinase-1 Alpha Using Virtual Screening and Molecular Dynamics Simulations. Pharmaceutics 2021, 13, 2157. https://doi.org/10.3390/ pharmaceutics 13122157

Academic Editor: Katarzyna Malarz

Received: 11 November 2021 Accepted: 6 December 2021 Published: 15 December 2021

Publisher's Note: MDPI stays neutral with regard to jurisdictional claims in published maps and institutional affiliations.

Copyright: (c) 2021 by the authors. Licensee MDPI, Basel, Switzerland. This article is an open access article distributed under the terms and conditions of the Creative Commons Attribution (CC BY) license (https:// creativecommons.org/licenses/by/ $4.0 /)$.
1 Department of Clinical Laboratory Sciences, College of Applied Medical Sciences, Taif University, P.O. Box 11099, Taif 21944, Saudi Arabia; dr.alaa.shafie.tu@gmail.com (A.S.); farahanjum@tu.edu.sa (F.A.)

2 Drug Discovery and Development Centre (H3D), University of Cape Town, Rondebosch 7701, South Africa; shamak361@gmail.com

3 Department of Computer Science, Jamia Millia Islamia, Jamia Nagar, New Delhi 110025, India; neelambeigh786@gmail.com

4 Centre for Interdisciplinary Research in Basic Sciences, Jamia Millia Islamia, Jamia Nagar, New Delhi 110025, India; taj144796@st.jmi.ac.in

5 Department of Biochemistry, College of Medicine, Prince Sattam Bin Abdulaziz University, Al-Kharj 11942, Saudi Arabia; mgulam@gmail.com

6 College of Pharmacy, Gachon University of Medicine and Science, Hambakmoeiro, Yeonsu-gu, Incheon City 21924, Korea

* Correspondence: dharmendra30oct@gmail.com (D.K.Y.); mihassan@jmi.ac.in (M.I.H.)

Abstract: Casein kinase-1 alpha $(\mathrm{CK} 1 \alpha)$ is a multifunctional protein kinase that belongs to the serine/threonine kinases of the CK $1 \alpha$ family. It is involved in various signaling pathways associated with chromosome segregation, cell metabolism, cell cycle progression, apoptosis, autophagy, etc. It has been known to involve in the progression of many diseases, including cancer, neurodegeneration, obesity, and behavioral disorders. The elevated expression of $\mathrm{CK} 1 \alpha$ in diseased conditions facilitates its selective targeting for therapeutic management. Here, we have performed virtual screening of phytoconstituents from the IMPPAT database seeking potential inhibitors of CK1 $\alpha$. First, a cluster of compounds was retrieved based on physicochemical parameters following Lipinski's rules and PAINS filter. Further, high-affinity hits against CK1 $\alpha$ were obtained based on their binding affinity score. Furthermore, the ADMET, PAINS, and PASS evaluation was carried out to select more potent hits. Finally, following the interaction analysis, we elucidated three phytoconstituents, Semiglabrinol, Curcusone_A, and Liriodenine, posturing considerable affinity and specificity towards the $\mathrm{CK} 1 \alpha$ binding pocket. The result was further evaluated by molecular dynamics (MD) simulations, dynamical cross-correlation matrix (DCCM), and principal components analysis (PCA), which revealed that binding of the selected compounds, especially Semiglabrinol, stabilizes CK1 $\alpha$ and leads to fewer conformational fluctuations. The MM-PBSA analysis suggested an appreciable binding affinity of all three compounds toward CK1 1 .

Keywords: casein kinase-1 alpha; phytoconstituents; drug discovery; virtual screening; molecular dynamics simulation; dynamical cross-correlation matrices; principal components analysis

\section{Introduction}

Casein kinase-1 alpha $(\mathrm{CK} 1 \alpha)$ belongs to the serine/threonine family of kinases and functions primarily as a regulator in various signaling pathways [1]. Human kinases are considered as attractive drug targets for cancer therapy [2-7]. Like other kinases, CK1 $\alpha$ performs multiple biological processes such as cell division, cell cycle, beta-catenin destruction and cell morphogenesis, signal transduction, WNT signaling pathway, etc. [8-14]. Pharmacological inhibition of $\mathrm{CK} 1 \alpha$ has been investigated as a potential therapy in various diseases, 
including cancers [15]. In particular, $\mathrm{CK} 1 \alpha$ controls the WNT signaling pathway, which is essential in driving hematologic malignancies [16]. It is considered an integral component of the WNT signaling or beta-catenin pathway and a potential drug target for cancer $[1,17]$. $\mathrm{CK} 1 \alpha$ has shown high expression in various types of cancers like lymphoma, brain, prostate, lymphoma, and leukemia [1,18-20]. The RNA expression of CK1 $\alpha$ is decreased in lung cancer, bladder cancer, and melanoma, which is in turn determined via the amount of protein expressed [1]. In progressed melanoma tumors, the downregulation of $\mathrm{CK} 1 \alpha$ is mediated by its methylation [1].

CK1 proteins contain an extremely conserved kinase domain at the $\mathrm{N}$-terminal and a diverse regulatory domain at the C-terminus [21]. As a serine/threonine kinases family member, CK1 $\alpha$ embodies the typical bilobal structure, consisting of beta-sheets at a smaller $\mathrm{N}$-terminal lobe and an $\alpha$-helical structure C-terminal lobe [22]. It consists of a conserved glycine-rich loop which forms the boundary of the ATP binding site and contributes the $\gamma$-phosphate moiety of ATP [22]. The ATP binding and active sites in CK1 $\alpha$ are Lys46 and Asp136, respectively. The uniqueness around the binding pocket of $\mathrm{CK} 1 \alpha$ facilitates its selective targeting for structure-based drug discovery. The structural features of CK $1 \alpha$ are depicted in Figure 1.

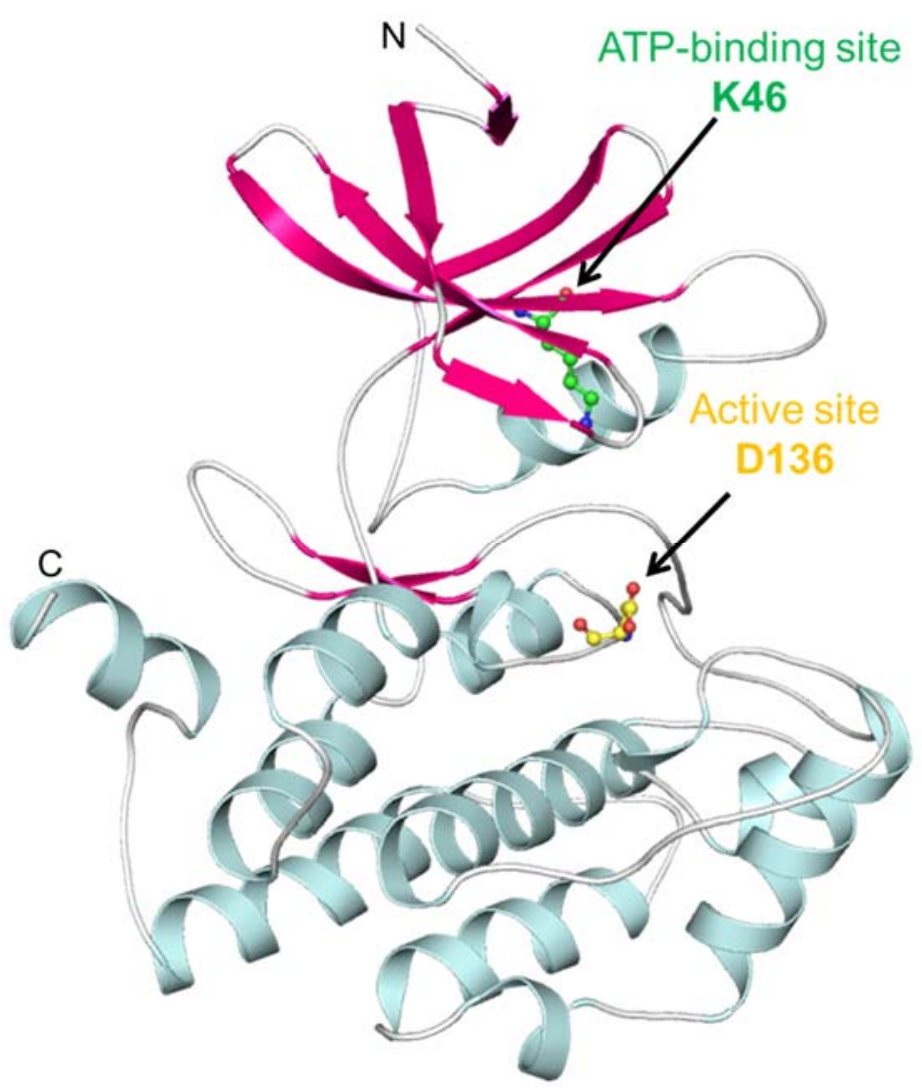

Figure 1. Structural features of Casein kinase $1 \alpha$. Structural components, sheets, helices, and loops are shown in pink, cyan, and grey-white, respectively. The figure was drawn in PyMOL using PDB ID: 6GZD.

Virtual screening has been an essential part of the drug discovery pipeline [23-26]. It helps find small molecules which could bind the defined target effectively and specifically [27-32]. It is one of the most effective techniques for identifying high-affinity binding partners to the target protein [23-25,33]. It computationally screens different chemical libraries available from various resources for identifying potential compounds [34-37]. The molecular docking-based virtual screening process, combined with several other filters, Lipinski's filter [38], ADMET properties, PAINS filter [39], PASS analysis [40], carcinogenicity prediction, etc., accelerate the lead discovery process. Natural compounds, including 
phytoconstituents, have been considered an important source of leads in drug discovery for ages [41,42].

In this study, we have considered $~ 9500$ phytoconstituents from the IMPPAT database, a curated database of phytochemicals of Indian medicinal plants. The compounds were subjected to screening based on Lipinski's rule of five, followed by molecular docking, ADMET properties, and PASS evaluation [40]. From the top hits generated, we have further screened the compounds based on their specific interactions towards the CK $1 \alpha$ binding pocket, followed by all-atom molecular dynamics (MD) simulations, dynamical cross-correlation matrix (DCCM), principal components analysis (PCA), and MM-PBSA analysis. Overall, the combined study suggests that three phytoconstituents, i.e., Curcusone A, Liriodenine, and Semiglabrinol targeting of $\mathrm{CK} 1 \alpha$, can be explored in the therapeutic management of cancer.

\section{Materials and Methods}

\subsection{Computer Environment and Web Resources}

This study was performed on an HP Z840 workstation running on Windows $10 \mathrm{OS}$. We used high-speed internet with an uninterrupted power supply. Bioinformatics tools such as MGL AutoDock [43] and InstaDock [44] were used for molecular docking-based virtual screening; PyMOL [45] and Discovery Studio visualizers [46] were used for interaction analysis and visualization purposes. Various web-based servers and resources, including RCSB Protein Data Bank (PDB), IMPPAT (Indian Medicinal Plants, Phytochemistry, and Therapeutics) database [47], SwissADME [48], pkCSM [49], PASS [40], etc. were utilized for the retrieval, evaluation, and analyses purposes.

\subsection{Receptor Preparation and Library Preparation}

The X-ray crystal structure of human CK1 $\alpha$ (PDB ID: 6GZD, resolution: $2.28 \AA$ ) was downloaded from the RCSB-PDB in the PDB format and refined further using the InstaDock tool, New Delhi, India. Using the PyMOL, the structure was visualized, and water molecules and heteroatom, including co-crystallized ligand, were removed. A database named IMPPAT was used for the screening purpose. The Lipinski filter was applied to the IMPPAT database so that only compounds with admirable physicochemical properties were fetched out. IMPPAT is a manually curated database of traditional Indian medicines and other existing resources of phytochemistry. It has a total of 9596 compounds which remained to 5763 after applying the Lipinski filter.

\subsection{Molecular Docking-Based Virtual Screening}

Virtual screening plays a vital role in drug discovery and development [50,51]. It aims to screen large libraries of drug-like compounds computationally, generally commercially available, against specific protein targets and reduce them to a key set of likely drug candidates [52,53]. Molecular docking-based virtual screening is based on interacting receptors and small molecules $[30,44,54,55]$. The docking protocol tries to predict the position and orientation of the ligand when it is bound to a protein [56-58]. The docking process must be fast enough as many compounds are being analyzed [59-62]. In this attempt of virtual screening, we begin with a 3D structure of CK1 $\alpha$ and a 3D database of phytoconstituents and score the compounds to identify lead candidates for further analysis. We used InstaDock to perform the molecular docking-based virtual screening. The docking screening was blind, where the search space was big enough to accommodate the protein's entire structure and let the ligands freely move and search their favorable binding sites. The resultant output was analyzed in out-files and log-files once InstaDock completed the docking. The top hits were fetched out based on the affinity score toward CK1 $1 \alpha$.

\subsection{ADMET Prediction}

The filtered compounds from the docking results were subjected to filter out based on their ADMET properties. The prediction of ADMET properties along with PAINS 
(Pan-assay interference compounds) [39] evaluation was carried out using the pkCSM and SwissADME [48]. Compounds with well ADMET properties were taken and then filtered for any PAINS patterns. PAINS filter helps us to avoid compounds having explicit patterns with a higher tendency of binding to multiple targets [39]. The ADMET evaluation helps find compounds with drug-like physicochemical and pharmacokinetic properties, which reduces their chances of failure in clinical trials [63].

\subsection{PASS Evaluation}

The PASS analysis is useful in studying the chemical-biological interactions to evaluate the biological properties of chemical compounds. We have used the PASS server to examine the biological properties of the selected compounds from the ADMET filter. The internal algorithm of the PASS webserver uses molecular fragments of chemical compounds as multi-level neighbors of atoms descriptors and recommends certain biological properties. It provided two different descriptors, i.e., 'probability to be active (Pa)' and 'probability of being inactive $(\mathrm{Pi})^{\prime}$, where a higher Pa value signifies a higher probability of corresponding property for the compound.

\subsection{Interaction Analysis}

The interaction analysis of the docked protein-ligand complexes was performed to explore various interactions formed during their binding. The binding poses and all possible interactions were explored through the PyMOL and Discovery Studio Visualizer. The interactions formed within $3.5 \AA$ within the protein-ligand complex were labeled as close contacts in the PyMOL. The type of interactions and the participating residual and atomic coordinates were explored through Discovery Studio Visualizer. Here, the compounds with specific interactions towards the critical residues of $\mathrm{CK} 1 \alpha$, including the active site and the binding site, were selected for further analyses. The binding of known $\mathrm{CK} 1 \alpha$ binding partners was referred to compare the docking outputs.

\subsection{Simulations}

\subsubsection{Systems Preparation and Simulation Protocol}

The apo $\mathrm{CK} 1 \alpha$ and its complexes with the selected ligands prepared through the molecular docking approach were used as initial coordinates in the MD simulation study. The all-atom MD simulations were performed through the AMBER 18 package [64]. The FF14SB AMBER force field [65] was used for the receptor protein, and appropriate charge and protonation state were prepared through the Protein Preparation Wizard implemented in the Schrödinger suite. The GAFF force field [66] was utilized for the ligands, and the AM1-BCC model [67] was used in parameterization and adding charges. The topology and atomic charges of the compounds were generated through the Antechamber utility of the AMBER 18 package. The topology and coordinates of the complex systems were generated through the leap module of AMBER 18. The solvation of all the systems was performed in a virtual box of the TIP3P water model [68]. An appropriate number of counterions was supplied for the neutralization of the systems. To deal with the hydrogen bonds and long-range electrostatic interactions, the SHAKE algorithm and the particle mesh Ewald (PME) was espoused, respectively. The energy minimization of all the systems was carried out using 10,000 steps of the steepest descent algorithm. Each system was gradually heated from 0 to $300 \mathrm{~K}$ for 100 ps. Afterward, the equilibration of each system was performed for $100 \mathrm{ps}$ at $300 \mathrm{~K}$ and constant pressure. Lastly, a production run for $200 \mathrm{~ns}$ for each system was performed at constant temperature and pressure. The resultant trajectories were explored using the CPPTRAJ module [69]. The RMSD, RMSF, $R_{\mathrm{g}}$, SASA, H-bonds, secondary structure analysis, distance cross-correlation matrix, and PCA were analyzed from the generated outputs. 


\subsubsection{Dynamical Cross-Correlation Matrix}

The analysis of the MD resultant trajectory was also performed through the dynamical cross-correlation matrices (DCCM). DCCM analysis helps us to determine the coordinate aberrations and behaviors in $\mathrm{C}_{\alpha}$ atoms of the protein [70]. In DCCM, all configurations are translated and rotated by the least-square-fitting method using all backbone $\mathrm{C}_{\alpha}$ atoms of $\mathrm{CK} 1 \alpha$ before and after the ligands binding to align on the equilibrated configurations. The technical concept of DCCM $\left(C_{i j}\right)$ is defined below:

$$
C_{i j}=\frac{\langle\Delta r i . \Delta r j\rangle}{\left(\left\langle\Delta r_{i}^{2}\right\rangle\left\langle\Delta r_{j}^{2}\right\rangle\right)^{\frac{1}{2}}}
$$

where $\Delta r_{i, j}$ signifies the ith and jth atom average point movement. Correlated movements are denoted by $C_{i j}=1$; however, $C_{i j}=-1$ is supposed to be highly anti-correlated. The divergence of atomic movements from 1 to -1 defines that $i$ and $j$ movements are correlated and anti-correlated.

\subsubsection{Principal Component Analysis}

Principal components analysis (PCA) is a highly useful approach in pattern recognition in protein movements [71]. In PCA, two-dimensional plotting of two different eigenvectors (EVs), i.e., EV1 and EV2, is produced by clustering them $[27,33,72,73]$. PCA was performed through the covariance matrix $C$, based on the atomic coordinates of $C_{\alpha}$ atoms and their corresponding eigenvalues [74]. The generation of positional covariance matrix $C$ is defined below:

$$
C_{i}=\left\langle\left(q_{i}-\left\langle q_{i}\right\rangle\right)\left(q_{j}-\left\langle q_{j}\right\rangle\right)\right\rangle \quad(i, j=1,2, \ldots, 3 N)
$$

where $q_{i}$ and $q_{j}$ represent the cartesian coordinates for the $i^{\text {th }}, j^{\text {th }}$ position of the $\mathrm{C}_{\alpha}$ atom and $\mathrm{N}$ is the number of $\mathrm{C}_{\alpha}$ atoms.

\subsubsection{MM-PBSA Calculations}

To further support the binding studies of CK1 with the selected compounds, the binding affinity of each docked complex was examined through the MM-PBSA calculations [75]. The binding energies of each complex were estimated by considering the vacuum potential energy, including bonded and non-bonded interactions, and the free energy of solvation, considering polar and nonpolar terms. The polar solvation energy was calculated by resolving the Poisson-Boltzmann equation, while the nonpolar solvation energy was estimated using the SASA method. The MM-PBSA estimation was carried out while utilizing the script 'MMPBSA.py' of the AMBER suite [76].

\section{Results and Discussion}

\subsection{Molecular Docking-Based Virtual Screening}

Molecular docking-based virtual screening of all the phytoconstituents from the IMPPAT was carried out to find high-affinity binding partners of CK $1 \alpha$. The resultant output generated the affinities and docked poses for each compound $[30,54,77]$. The compounds were filtered out based on their binding affinity towards CK1 $\alpha$. The selected compounds were found to possess appreciable binding affinity towards the binding pocket of CK1 $\alpha$ (Table 1). The top 10 hits out of 5763 compounds had the binding affinity score $\leq-9.7$ with CK $1 \alpha$ (Table 1). The results indicated that the selected phytoconstituents have appreciable binding efficiency with $\mathrm{CK} 1 \alpha$, further exploring the therapeutic potential in the drug development process. 
Table 1. The top 10 hits and their binding affinities toward CK1 $\alpha$.

\begin{tabular}{|c|c|c|c|c|c|c|}
\hline S. No. & Compound ID & Phytochemical Name & Source & $\underset{(\mathrm{kcal} / \mathrm{mol})}{\text { Binding Affinity }}$ & $\mathrm{pKi}$ & $\begin{array}{l}\text { * Ligand } \\
\text { Efficiency }\end{array}$ \\
\hline 1. & 443716 & Hydroxysanguinarine & $\begin{array}{c}\text { Papaver } \\
\text { somniferum }\end{array}$ & -10.1 & 7.41 & 0.33 \\
\hline 2. & 94577 & Cepharadione A & Piper nigrum & -10.0 & 7.33 & 0.33 \\
\hline 3. & 11035494 & Semiglabrinol & $\begin{array}{l}\text { Tephrosia } \\
\text { purpurea }\end{array}$ & -9.9 & 7.26 & 0.30 \\
\hline $\begin{array}{l}4 . \\
5 .\end{array}$ & $\begin{array}{l}124069 \\
175941\end{array}$ & $\begin{array}{l}\text { Dihydrosanguinarine } \\
\text { Curcusone A }\end{array}$ & $\begin{array}{l}\text { Fumaria indica } \\
\text { Jatropha curcas }\end{array}$ & $\begin{array}{l}-9.8 \\
-9.8\end{array}$ & $\begin{array}{l}7.19 \\
7.19\end{array}$ & $\begin{array}{l}0.33 \\
0.39\end{array}$ \\
\hline 6. & 10144 & Liriodenine & $\begin{array}{l}\text { Annona } \\
\text { squamosa }\end{array}$ & -9.8 & 7.19 & 0.38 \\
\hline 7. & 147329 & Corysamine & $\begin{array}{l}\text { Meconopsis } \\
\text { aculeata }\end{array}$ & -9.7 & 7.11 & 0.33 \\
\hline 8. & 197018 & Ushinsunine & $\begin{array}{l}\text { Michelia } \\
\text { champaca }\end{array}$ & -9.7 & 7.11 & 0.31 \\
\hline $\begin{array}{l}9 . \\
10 .\end{array}$ & $\begin{array}{c}2754650 \\
442851\end{array}$ & $\begin{array}{l}\text { Irenolone } \\
\text { Crinasiatine }\end{array}$ & $\begin{array}{l}\text { Musa paradisiaca } \\
\text { Crinum asiaticum }\end{array}$ & $\begin{array}{l}-9.7 \\
-9.7\end{array}$ & $\begin{array}{l}7.11 \\
7.11\end{array}$ & $\begin{array}{l}0.35 \\
0.33\end{array}$ \\
\hline
\end{tabular}

${ }^{*}$ Ligand Efficiency values are in $(\mathrm{kcal} / \mathrm{mol} / \mathrm{non}-\mathrm{H}$ atom); S. No., serial number.

\subsection{ADMET Properties}

ADMET prediction consists of a set of parameters on which the pharmacokinetic properties of chemical compounds have to be depicted [29,30,78]. The selected hits from the docking study were further screened to predict their ADMET properties (Table 2). The three compounds out of 10 having ADMET within the range of drug candidacy were selected. These three compounds (Semiglabrinol, Curcusone_A, and Liriodenine) share a similar class of ADMET properties without any toxic patterns (AMES/Hepatotoxicity) thus were selected for further analysis.

Table 2. ADMET properties of the top 10 compounds.

\begin{tabular}{|c|c|c|c|c|c|c|c|}
\hline \multirow[b]{2}{*}{ S. No. } & \multirow[b]{2}{*}{ Compound } & \multicolumn{2}{|c|}{ Absorption } & \multirow{2}{*}{$\begin{array}{c}\text { Distribution } \\
\text { BBB } \\
\text { Permeation }\end{array}$} & \multirow{2}{*}{$\begin{array}{c}\text { Metabolism } \\
\text { CYP2D6 } \\
\text { Sub- } \\
\text { strate/Inhibitor }\end{array}$} & \multirow{2}{*}{$\begin{array}{c}\text { Excretion } \\
\text { OCT2 } \\
\text { Substrate }\end{array}$} & \multirow{2}{*}{$\begin{array}{c}\text { Toxicity } \\
\text { AMES/ } \\
\text { Hepatotoxicity }\end{array}$} \\
\hline & & $\underset{\text { Absorption }}{G I}$ & $\begin{array}{c}\text { Water } \\
\text { Solubility }\end{array}$ & & & & \\
\hline 1. & Hydroxysanguinarine & High & Moderate & Yes & No & No & Yes \\
\hline 2. & Cepharadione A & High & Moderate & Yes & No & No & Yes \\
\hline 3. & Semiglabrinol & High & Moderate & Yes & No & No & No \\
\hline 4. & Dihydrosanguinarine & High & Moderate & Yes & No & No & Yes \\
\hline 5. & Curcusone A & High & Moderate & Yes & No & Yes & No \\
\hline 6. & Liriodenine & High & Moderate & Yes & Yes & No & No \\
\hline 7. & Corysamine & High & Moderate & Yes & Yes & Yes & Yes \\
\hline 8. & Ushinsunine & High & High & Yes & Yes & No & Yes \\
\hline 9. & Irenolone & High & Moderate & Yes & Yes & No & Yes \\
\hline 10. & Crinasiatine & High & Moderate & Yes & Yes & No & Yes \\
\hline
\end{tabular}

S. No., serial number; GI absorption, gastrointestinal absorption; BBB permeation, blood-brain barrier permeation.

\subsection{PASS Evaluation}

Natural compounds possess many chemico-biological properties, which may consequence in synergistic or antagonistic impacts [41,79]. In search of safe and effective compounds with desirable properties, the biological properties for the hit molecules need to be explored. In this study, the PASS analysis explored the probable properties of the elucidated hits. The compounds and their biological properties are summarized in Table 3 , along with their confidence level. The results revealed that the selected hits, Semiglabrinol, Curcusone_A, and Liriodenine, possess antineoplastic and kinase inhibitory potential, with significant Pa values, i.e., 0.612 to 0.889 . The PASS analysis recommended that Curcusone_A, Liriodenine, and Semiglabrinol have great potential in anticancer therapeutics. 
Table 3. Biological properties of the elucidated phytoconstituents predicted through the PASS webserver.

\begin{tabular}{cccc}
\hline Compound ID & $\mathbf{P a}$ & $\mathbf{P i}$ & Biological Activity \\
\hline \multirow{3}{*}{ Semiglabrino } & 0.808 & 0.005 & Kinase inhibitor \\
& 0.793 & 0.011 & Membrane permeability inhibitor \\
& 0.783 & 0.014 & Antineoplastic \\
& 0.653 & 0.036 & TP53 expression enhancer \\
& 0.612 & 0.033 & Oxidoreductase inhibitor \\
& 0.889 & 0.005 & Antineoplastic \\
Curcusone_A & 0.819 & 0.015 & Antieczematic \\
& 0.803 & 0.004 & Carminative \\
& 0.744 & 0.004 & Transcription factor NF kappa B \\
& 0.702 & 0.015 & stimulant \\
& 0.784 & 0.014 & Apoptosis agonist \\
& 0.763 & 0.008 & Antineoplastic \\
Liriodenine & 0.710 & 0.015 & Caspase 3 stimulant \\
& 0.680 & 0.014 & Alkane 1-monooxygenase inhibitor \\
& 0.629 & 0.005 & Kinase inhibitor \\
& & & Caspase 8 stimulant \\
\hline
\end{tabular}

\subsection{Interaction Analysis}

The selected compounds' binding modes and interaction patterns were analyzed utilizing PyMOL and Discovery Studio visualizer. The analysis of compounds was done based on interacting residues. We employed Discovery Studio and PyMOL to identify and visualize hydrogen bonding and other interactions of the compounds with CK1 $\alpha$. It was found that residues of the kinase domain of CK1 $\alpha$ offer a significant number of interactions, such as Ser25, Lys46, and Leu93 (Figure 2). The ATP binding site, i.e., Lys46, was also found to make direct contact with the docked compounds, which is crucial for the CK1 $\alpha$ activity (Figure 2B). All three compounds were found to be fit within the binding pocket of CK1 $\alpha$ with a good complementarity (Figure 2C).
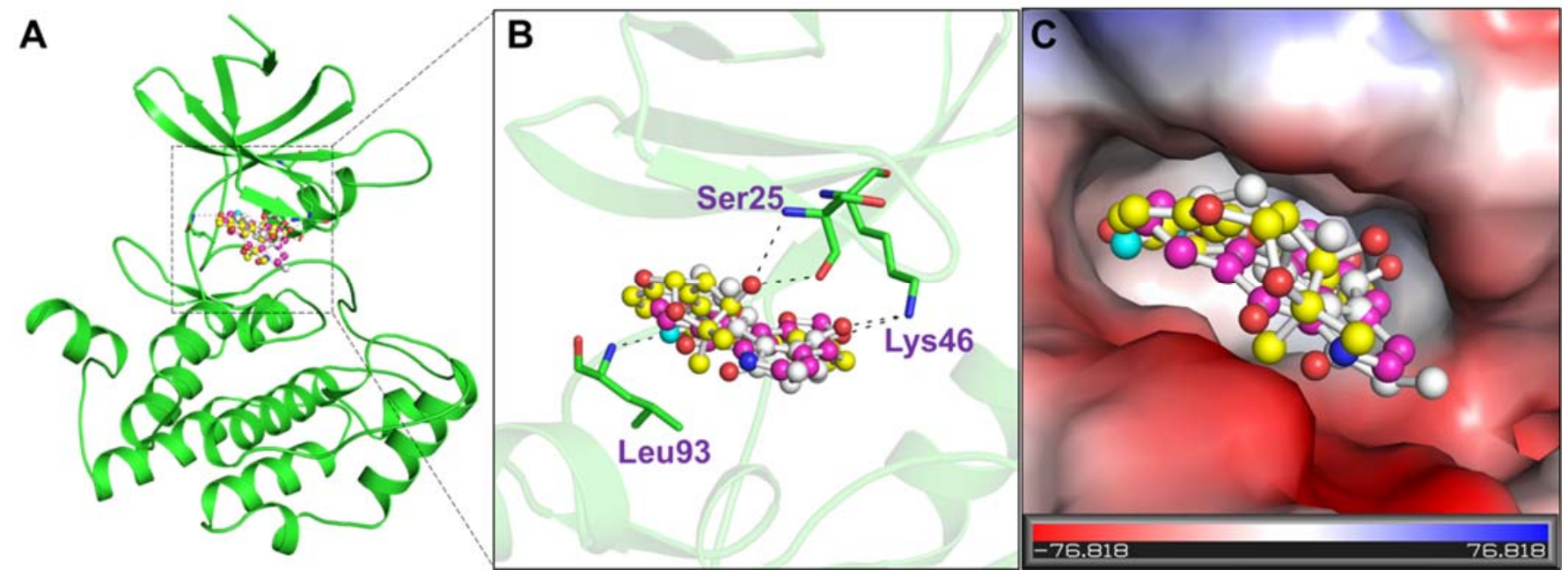

Figure 2. Molecular interactions of (A) Casein kinase 1 with Curcusone A (white), Liriodenine (magenta), and Semiglabrinol (yellow). (B) Magnified cartoon view of protein-ligands interactions. (C) Electrostatic potential of Casein kinase 1 bound the selected compounds.

The detailed binding analysis showed that the interaction of all three compounds was in the ATP binding pocket, where several crucial residues of CK1 $\alpha$ participated in the interaction (Figure 3). The binding of all three compounds with CK1 $\alpha$ was stabilized 
by several interactions, including four conventional $\mathrm{H}$-bonds, one carbon- $\mathrm{H}$ bond, and a few hydrophobic interactions. The plot showed that two H-bonds stabilized the CK1 $1 \alpha-$ Curcusone_A complex with Gly26 and Lys46, two Alkyl bonds with Ile23 and Ile31, along with 15 Van der Waals interactions (Figure 3A). While one H-bond stabilized the CK1 $\alpha-$ Liriodenine complex with Lys46, two Alkyl bonds with Ile31 and Ala44, along with two Pi-sigma bonds with Leu143 and Ile156, and 10 Van der Waals interactions (Figure 3B). At the same time, the CK1 $\alpha$-Semiglabrinol complex was stabilized by two $\mathrm{H}$-bonds with Ser25 and Ile93, along with several other interactions (Figure 3C). The stable binding of the elucidated compounds with the ATP-binding site might be vital to inhibit the kinase activity of $\mathrm{CK} 1 \alpha$ and raise them as "competitive inhibitors" of CK1 $\alpha$.

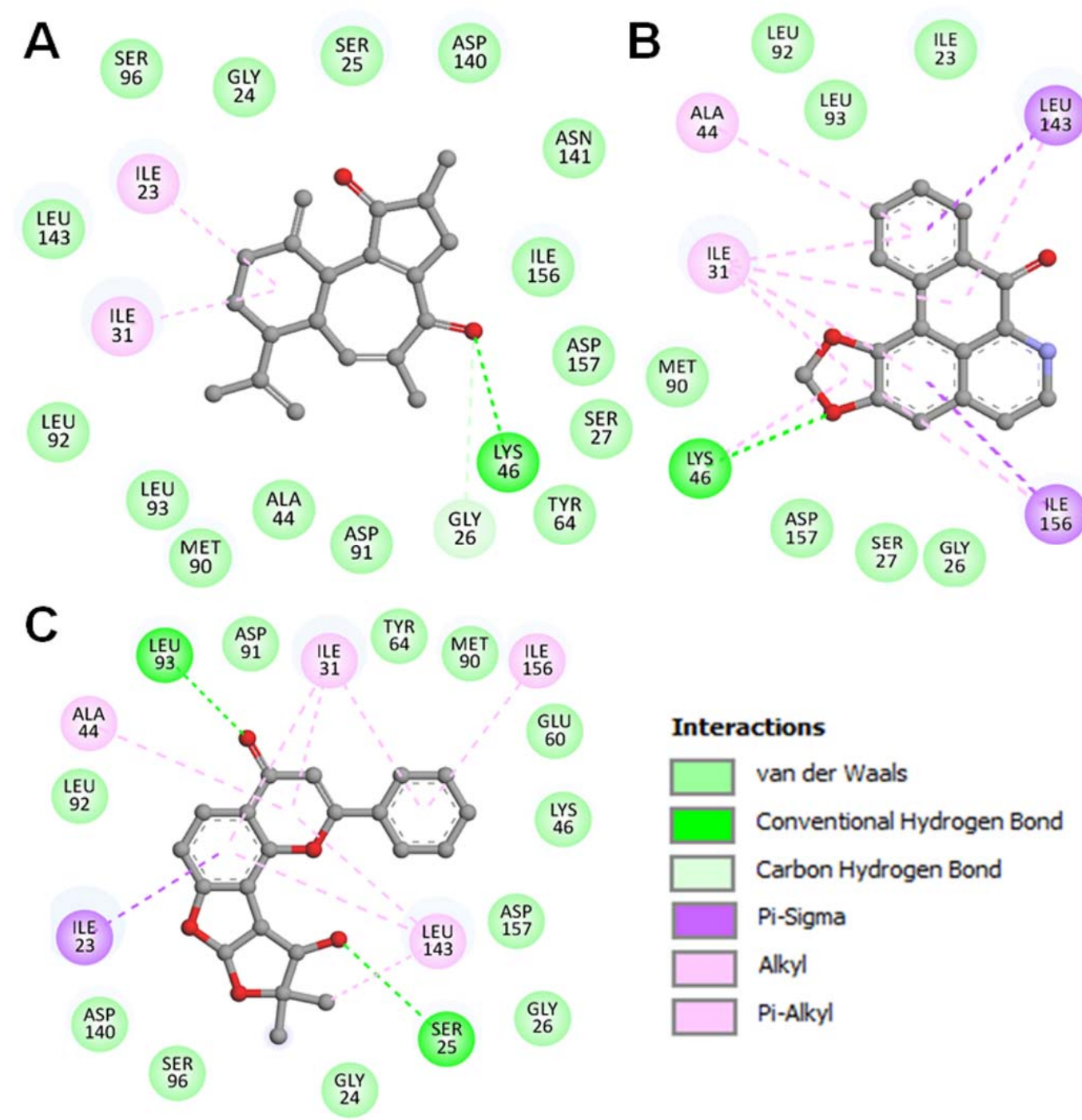

Figure 3. Representation of Molecular Interaction and 2D plots showing detailed interactions of (A) Curcusone A, (B) Liriodenine, and (C) Semiglabrinol with CK1 $\alpha$.

\subsection{Simulations}

\subsubsection{Structural Deviations in $\mathrm{CK} 1 \alpha$}

Docking study can only provide a static prototype for protein-ligand interactions; hence, MD simulation studies were carried out on CK1 $\alpha$ and its docked complexes with Curcusone_A, Liriodenine, and Semiglabrinol to explore their binding mechanism. To assess the structural deviations in $\mathrm{CK} 1 \alpha$ and its docked complexes, the systematic properties of each complex, such as RMSD and RMSF, were examined during the simulation time. The 
fluctuations of RMSD values in each system are depicted in Figure 4A, which indicates that all of them are stable without any major fluctuation during the $200 \mathrm{~ns}$ MD trajectories. The RMSD values of $C \alpha$ backbone atoms denoting the starting structure were used to observe the dynamic stability of the complexes. The RMSD results revealed that each complex reached equilibrium after $50 \mathrm{~ns}$ which are quite stable up to the simulation trajectory.
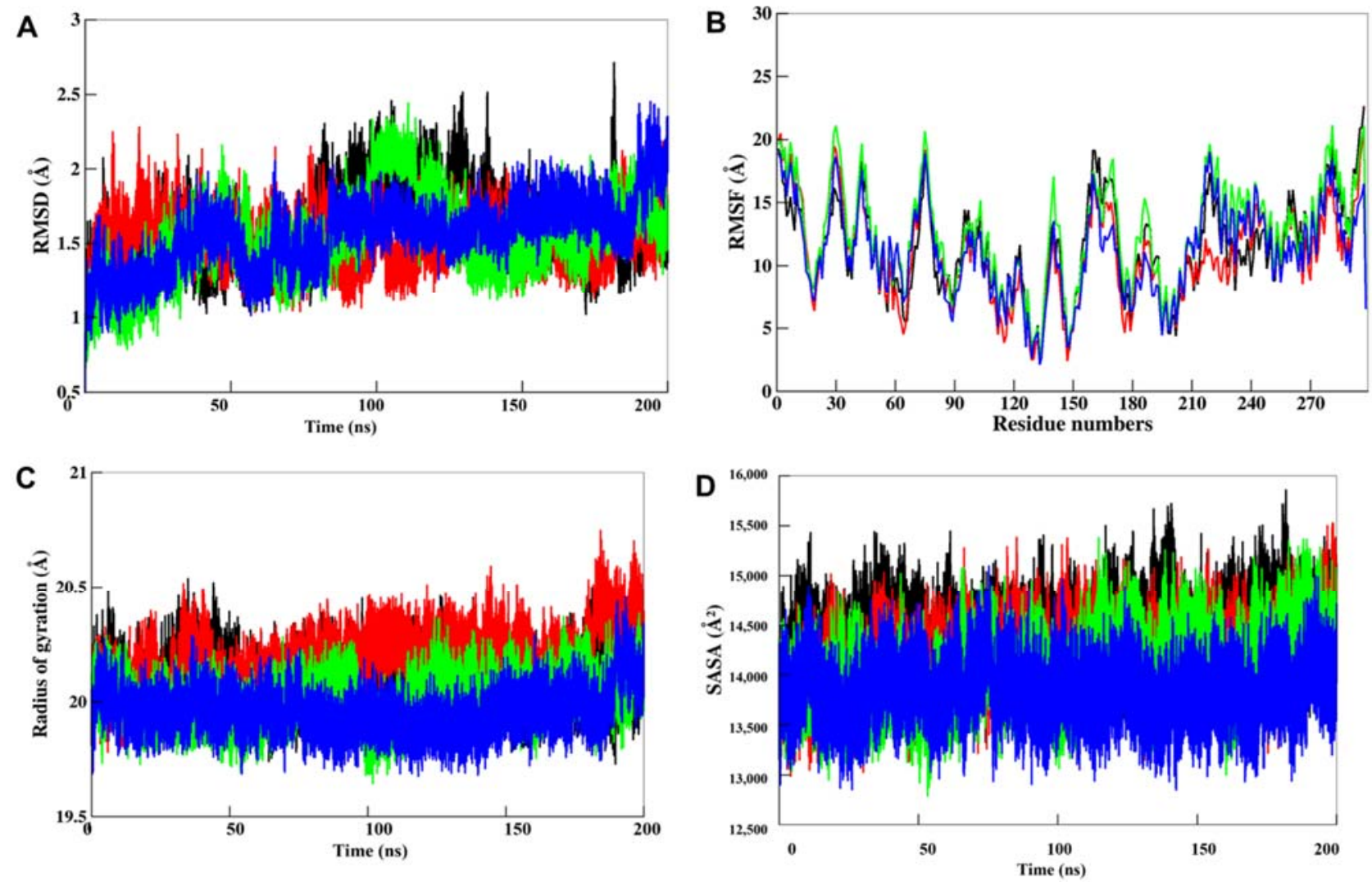

Figure 4. Structural dynamics of CK1 $\alpha$ Apo (black), CK1 $1 \alpha$-Curcusone_A (red), CK1 $\alpha$-Liriodenine (green), and CK1 $\alpha$ Semiglabrinol (blue) (A) RMSD, (B) RMSF, (C) Rg, and (D) SASA across C $\alpha$ backbone calculated after $200 \mathrm{~ns}$ of MD trajectories.

To evaluate the stability of the binding pocket residues in MD simulation, the RMSF of all the residues in CK1 $\alpha$ were calculated and plotted [80-84]. During the RMSF calculation, the average fluctuation of each residue of $\mathrm{CK} 1 \alpha$ before and after the binding of the compounds was computed for the entire $200 \mathrm{~ns}$ trajectories of MD simulation. The RMSF results showed that residues around the ligand-binding site are less fluctuated than other regions, suggesting that the binding pocket is relatively stable during the simulation time (Figure 4B).

The $R_{g}$ is another useful tool to explore the compactness of a protein and protein-ligand complex $[53,85]$. A higher $R_{g}$ value for a protein indicates its loose packing, while; lower $R_{g}$ value indicates tight packing of the structure. In MD studies, it is used to demonstrate the impact of a ligand molecule, exerting conformational changes in protein molecules. We have evaluated the $R_{g}$ of each complex during the simulation to see the impact of compounds binding on the conformational packing of CK1 $\alpha$ (Figure 4C). The results showed that CK $1 \alpha$ had the lowest $R_{g}$ value during the simulation when in complexed with Semiglabrinol, which could be attributed to a more compact structure than the free state of $\mathrm{CK} 1 \alpha$. However, the results indicated that the ligand binding to CK1 $\alpha$ doesn't affect its compactness and supports complex stability.

To further evaluate the folding/unfolding behavior of CK $1 \alpha$ before and ligand binding, we have calculated the time evolution of SASA values during the simulation. The SASA values represent the exposure of each amino acid in a protein surrounded by the 
solvent. The plotted SASA values are in good agreement with the $R_{g}$ trend of the simulated trajectories of $200 \mathrm{~ns}$ (Figure 4D). The plot showed that SASA is decreased after the binding of a ligand, especially in the case of Semiglabrinol, which suggested higher compactness and stability of the docked complexes during the simulation. After the 100 ns simulation, the SASA values of the CK1 $1 \alpha$-Liriodenin rise up slightly in the rest of the simulation time, which indicated an exposer of some buried residues to the solvent, but without any structural shift.

\subsubsection{Dynamics of Hydrogen Bonds}

Intramolecular H-bonds formation is quite important in maintaining the integrity of protein structure [86]. The analysis of intramolecular H-bonds during MD simulation is useful to examine the impact of ligand binding on the protein structure. At the same time, the analysis of intermolecular H-bonds is useful to see the lifetime of interactions formed between the protein and ligand. This work monitored the time evolution of H-bonds, with the distance cutoff set to $3.5 \AA$. The resultant plots of intramolecular and intermolecular H-bonds analysis for all the four systems in MD simulations are shown in Figure 5. The generated plot showed an overlapped pattern of intermolecular H-bonds distribution that suggested that CK1a maintained its structural integrity during the simulation even after compounds binding (Figure 5A). This analysis of intermolecular H-bonding also indicated that the compounds haven't moved from their initial docking position on CK $1 \alpha$ and maintain the interactions in stabilizing the complex structures (Figure 5B).
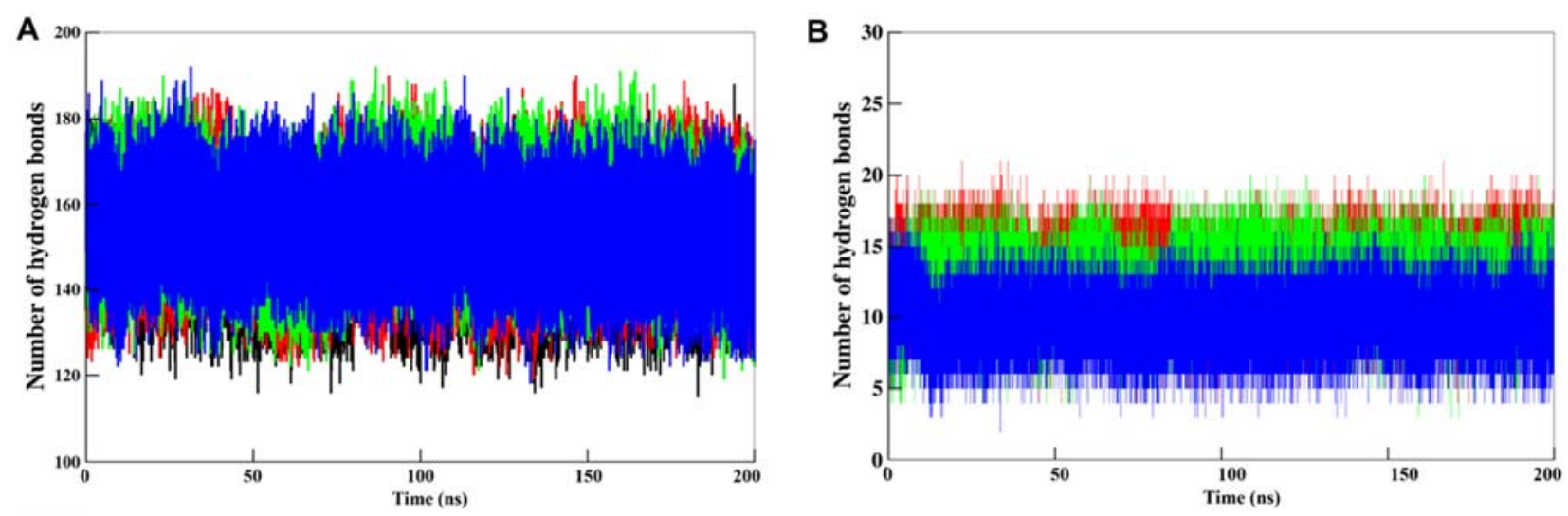

Figure 5. The dynamics of H-bonds in CK1 $\alpha$. (A) Intramolecular and (B) Intermolecular hydrogen bond analysis in CK1-Curcusone_A (red), CK1-Liriodenine (green), and CK1-Semiglabrinol (blue) calculated after 200 ns MD simulation.

\subsubsection{Secondary Structure Dynamics}

Secondary structure components in a protein maintained its 3D structure and regulated the flexibility/rigidity of the protein in a natural system [87-90]. To see the impact of compounds binding on $\mathrm{CK} 1 \alpha$, the dynamics of secondary structure components were monitored (Figure 6). The generated graphs show the participation of each residue in secondary structure formation overtime during the entire simulation. The secondary structure panels of each system generated through the simulated trajectory indicated the stable pattern over $200 \mathrm{~ns}$ simulation. The result suggested that secondary structure components of $\mathrm{CK} 1 \alpha$ protein are conserved before and after the binding of each compound during the entire simulation. The average number of residues participating in the secondary structure formation is summarized in (Table 4). 

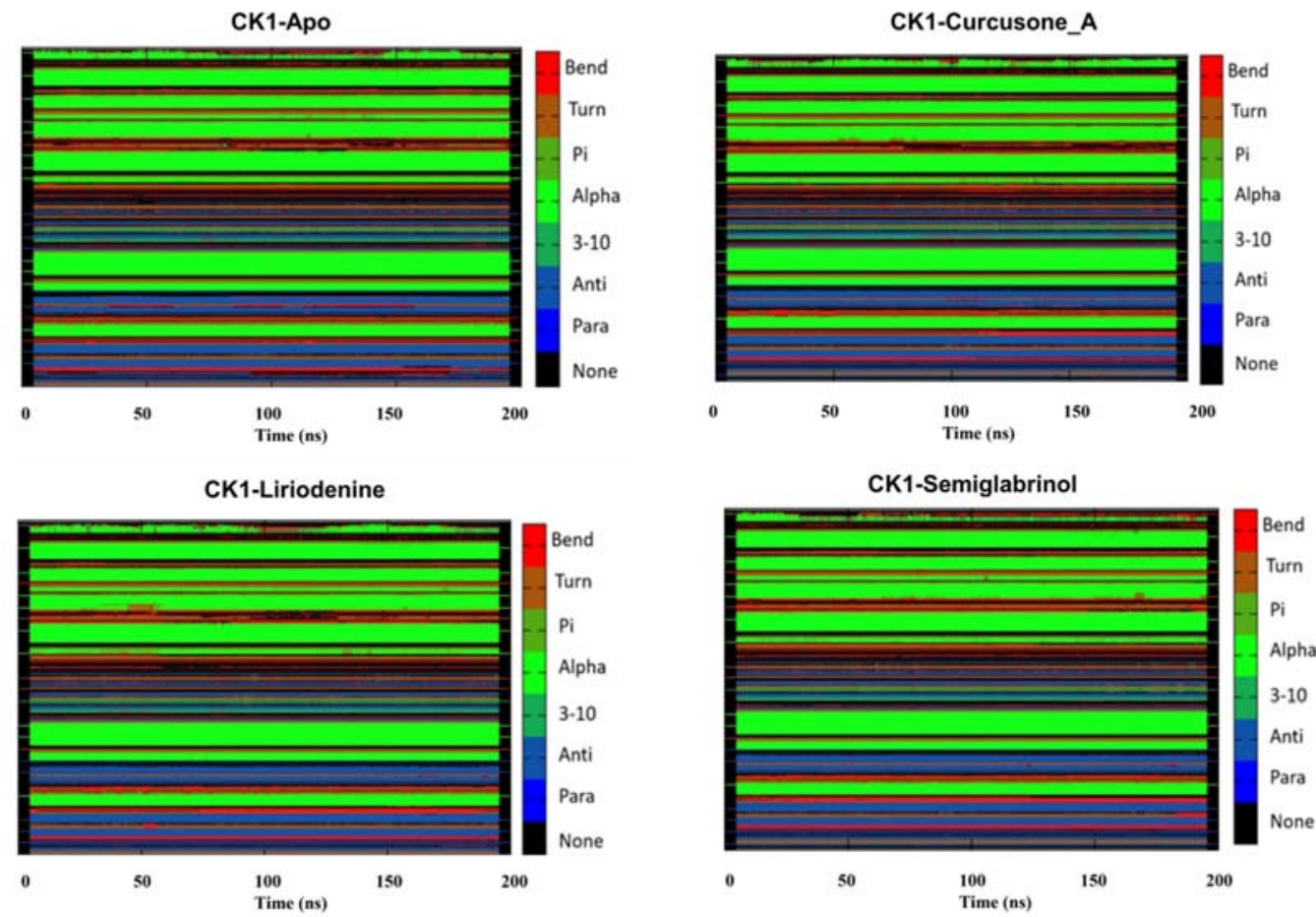

Figure 6. Secondary structural analysis of CK1 $\alpha$ Apo, CK1 $\alpha$-Curcusone_A, CK1 $\alpha$-Liriodenine and $\mathrm{CK} 1 \alpha$-Semiglabrinol complexes calculated after $200 \mathrm{~ns}$ of MD trajectories.

Table 4. Percentage of amino acid residues contributed to the secondary structure of CK1 $\alpha$ Apo, CK1 $\alpha$-Curcusone_A, CK1 $\alpha$-Liriodenine and CK1 $\alpha$-Semiglabrinol complexes calculated after $200 \mathrm{~ns}$ of MD trajectories.

\begin{tabular}{ccccccc}
\hline Complex & $\boldsymbol{\alpha}$ & $\boldsymbol{\beta}$ & $\mathbf{3}_{\mathbf{1 0}}$-Helix & Turn & Bend & Other \\
\hline CK1 $\alpha$-Apo & 24 & 23 & 3 & 9 & 11 & 19 \\
CK1 $\alpha$-Curcusone_A & 21 & 19 & 5 & 10 & 8 & 21 \\
CK1 $\alpha$-Liriodenine & 27 & 23 & 6 & 12 & 10 & 18 \\
CK1 $\alpha$-Semiglabrinol & 28 & 26 & 7 & 13 & 14 & 24 \\
\hline
\end{tabular}

However, a slight decrement in $\alpha$-helices and $\beta$-sheets in the case of CK1 $\alpha$-Curcusone_A was observed, possibly due to its increased dynamics as seen in the RMSF and SASA analyses. Whereas, a slight increase in the average number of residues that participated in the formation of $\alpha$-helices and $\beta$-sheets of CK1 $\alpha$ was observed after the Semiglabrinol binding, which suggested more compactness and stability of the docked complex during the simulation.

\subsubsection{DCCM}

Motions in a protein take place on a comprehensive range of time scales, extending from femtoseconds to seconds [91]. DCCM also depends on the time scale over which the correlation data was composed [92]. To explore the correlated and anti-correlated movements in CK1 $\alpha$ and its docked complexes with Curcusone_A, Liriodenine, and CK1 $\alpha$-Semiglabrinol, the inter-residue DCCM analysis was carried out. Four DCCM plots generated for the $\mathrm{CK} 1 \alpha$ and its docked complexes are illustrated in Figure 7. Positive and negative correlations are shown in red and blue, respectively. The maps indicated that $\mathrm{CK} 1 \alpha$ scattered into different populations through positive and negative correlations with reference to the residue index. The movements in all maps were relatively alike with minor fluctuations, suggesting that $\mathrm{CK} 1 \alpha$ may have similar global dynamics before and after compound binding. Overall, the correlation patterns in all the graphs are weakly 
differentiated, suggesting the stability of the movements in free CK $1 \alpha$ and its ligandbound complexes.
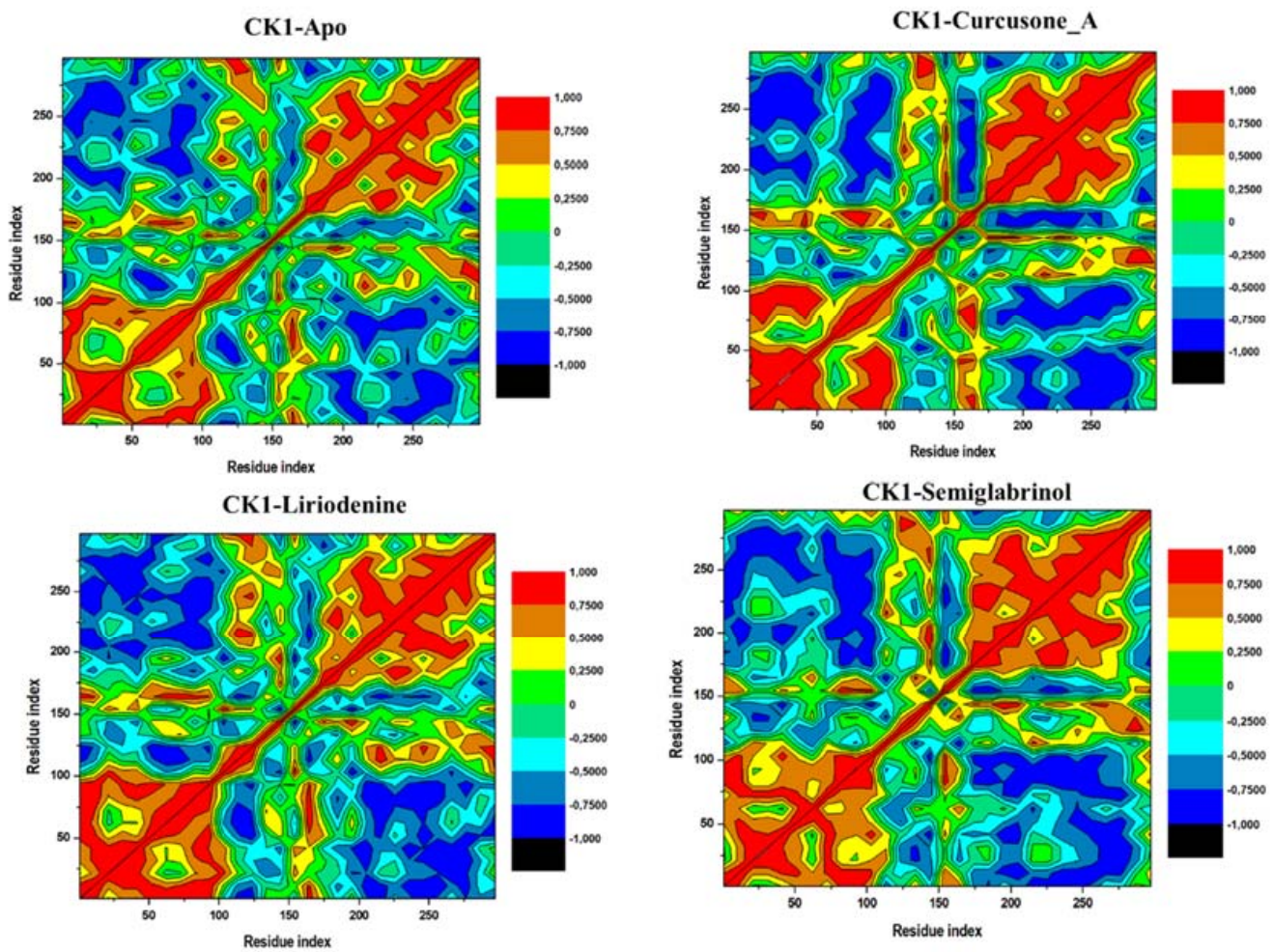

Figure 7. Dynamical cross-correlation matrices of the Apo CK $1 \alpha, \mathrm{CK} 1 \alpha$-Curcusone_A, CK $1 \alpha$ Liriodenine and $\mathrm{CK} 1 \alpha$-Semiglabrinol complexes.

\subsubsection{PCA}

PCA is a useful approach in figuring out the overall combined motions of the $\mathrm{C} \alpha$ atoms in a protein represented by the EVs of the covariance matrix [93]. It is used to explore the collective motions and conformational sampling of a protein and protein-ligand complex [94,95]. Employing PCA has been a valuable approach to studying the folding dynamics of a protein in the presence of small molecules $[26,96,97]$. To further explore the directionality of the conformational motions in CK1 $\alpha$, we carried out the PCA of all four simulation trajectories (Apo CK1 $1 \alpha, \mathrm{CK} 1 \alpha$-Curcusone_A, CK $1 \alpha$-Liriodenine, and CK1 $\alpha$ Semiglabrinol) (Figure 8). The average of the protein motions was designated based on the $\mathrm{C} \alpha$ atoms of $\mathrm{CK} 1 \alpha$. The projections conformations for the first two EVs, EV1, and EV2 indicated that $\mathrm{CK} 1 \alpha$ in complexed with Curcusone_A has significantly higher negative motions than the apo $\mathrm{CK} 1 \alpha$ and its other complexes. The results suggested CK $1 \alpha$-Semiglabrinol higher stable that mimicked the motions of the apo CK1 $\alpha$ with some positive movements. In all four projections, the CK $1 \alpha$-Curcusone_A and CK1 $\alpha$-Liriodenine complexes occupied a broader phase space as compared to the Apo CK1 $\alpha$ and CK $1 \alpha$-Semiglabrinol complex (Figure 8A). The collective motions of the CK1 $\alpha$-Semiglabrinol complex may plausibly enhance the stability of the docked complex compared to others. The directionality and magnitudes of all four trajectories were also explored through porcupine plots (Figure 8B). The changes in direction and magnitude of the complexed systems indicated that the binding of the identified compounds induced a minor conformational impact on the conformational dynamics of $\mathrm{CK} 1 \alpha$ but a quite stabilization during the simulation. 

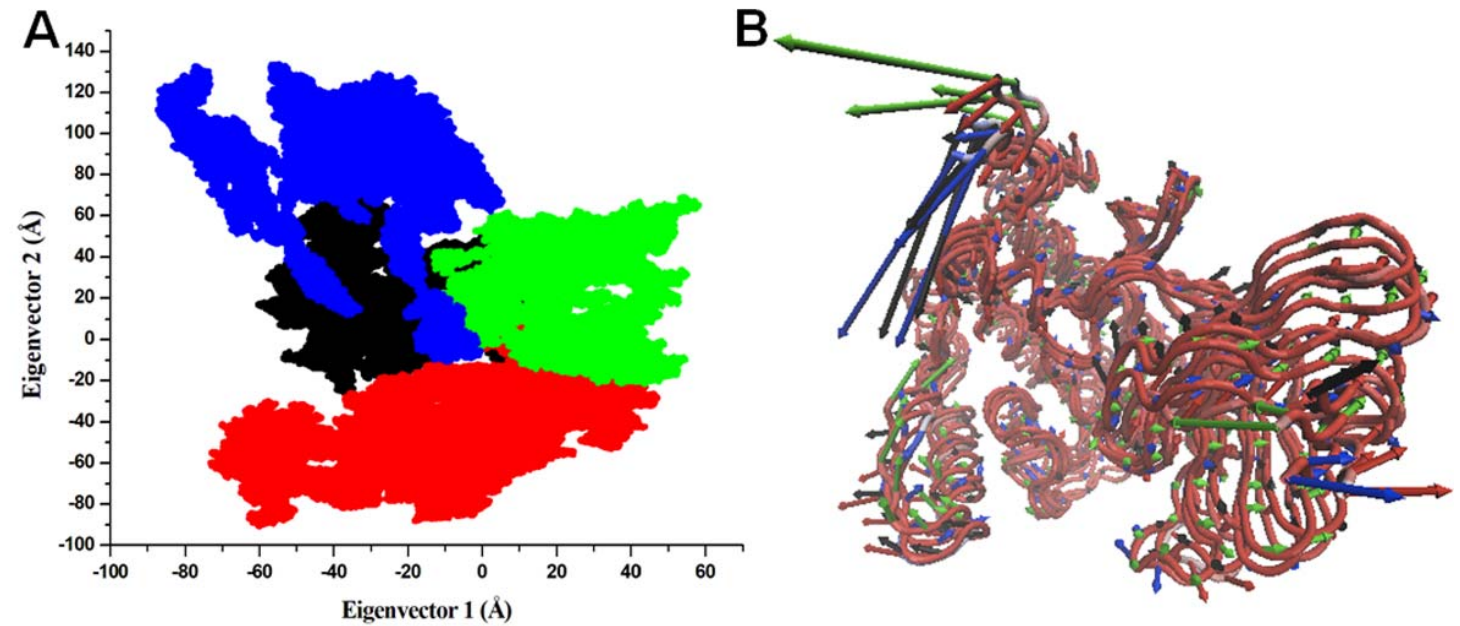

Figure 8. Principal component analysis. (A) $2 \mathrm{D}$ projection of CK1 $1 \alpha$ Apo (black), CK1 $1 \alpha$-Curcusone_A (red), CK $1 \alpha$ Liriodenine (green), and CK1 $\alpha$-Semiglabrinol complex calculated after $200 \mathrm{~ns}$ of MD trajectories (bule). (B) PC1 collective motions in porcupine plot for Apo, Curcusone_A, Liriodenine, and Semiglabrinol CK1 $\alpha$ complexes.

\subsubsection{MMPBSA}

The solvent condition is one of the crucial parameters while determining the binding affinity of a ligand molecule with a protein, which is typically not considered in molecular docking studies [98]. Therefore, the binding energies of all three docked complexes were further obtained through MM-PBSA calculations using the simulated MD trajectories. The binding energies of all three docked complexes are summarized in Table 5. The calculated binding energy through the MM-PBSA approach includes different energetic terms for the bonded and non-bonded (van der Waals and electrostatic) interactions. The MM-PBSA calculation was performed on the last $50 \mathrm{~ns}$ of the production run. The calculated results showed that Semiglabrinol in complex with CK1 $\alpha$ has the best result in MM-PBSA binding energy, further suggesting their higher stability than others. MM-PBSA result showed that the docked complex of Semiglabrinol with $\mathrm{CK} 1 \alpha$ was stabled with a binding affinity $(\Delta G)-41.08 \mathrm{kcal} / \mathrm{mol}$. The negative value of $\Delta \mathrm{E}_{\text {ele }}$ as compared to $\Delta \mathrm{E}_{\mathrm{vdW}}$ and $\Delta G_{\text {nonpolar }}$ signified the presence of $\mathrm{H}$-bonds and polar interactions between the $\mathrm{CK} 1 \alpha$ and the ligands, especially Semiglabrinol. Overall, the MMPBSA analysis confirmed the stability of all the docked complexes.

Table 5. MM-GBSA energy profiles of CK1 $\alpha$ in complex with Curcusone_A, Liriodenine, and Semiglabrinol *.

\begin{tabular}{cccccccc}
\hline Complex & $\Delta$ EvdW & $\Delta$ Eele & $\Delta$ Ggas & $\Delta$ Gpolar & $\Delta$ Gnonpolar & $\Delta$ Gsol & $\Delta$ Gbind \\
\hline CK1 $\alpha$-Curcusone_A & -45.23 & -8.27 & -53.50 & 20.77 & -5.74 & 15.03 & -38.47 \\
CK1 $\alpha$-Liriodenine & -38.60 & -9.31 & -47.91 & 20.77 & -4.24 & 16.53 & -31.38 \\
CK1 $\alpha$-Semiglabrinol & -43.58 & -1.98 & -45.56 & 9.54 & -5.06 & 4.47 & -41.08 \\
\hline
\end{tabular}

* All the values are in $\mathrm{kcal} / \mathrm{mol}$.

\section{Conclusions}

Considering $\mathrm{CK} 1 \alpha$ as a potential therapeutic target because of its presence as a positive regulator of cancer progression and targeting it with the selected hits is an attractive strategy. The computational approach used in this study might prove its usefulness in developing potential leads from natural compounds as potent inhibitors of $\mathrm{CK} 1 \alpha$ against cancer. We performed a systematic study of the structure-based drug discovery approach and identified three phytoconstituents, Semiglabrinol, Curcusone_A, and Liriodenine, evaluated as potent binding partners of $\mathrm{CK} 1 \alpha$. Initially, the compound database was filtered out based on several drug-like properties, followed by molecular docking study. Then, the results were validated by investigating RMSD, RMSF, $R_{g}$, SASA, and intra- and 
intermolecular H-bonding analyses in MD simulations followed by DCCM, and PCA. The integrated approach was used to assure that the selected hits interact properly with CK $1 \alpha$ with considerable stability. The MM-PBSA analysis further indicates that the elucidated phytoconstituents can act as promising $\mathrm{CK} 1 \alpha$ inhibitors and further be exploited for drug design purposes.

Author Contributions: Conceptualization, A.S., Z. and T.M.; methodology, S.K. and T.M.; software, F.A.; validation, G.M.H., D.K.Y. and Z.; formal analysis, A.S.; investigation, S.K.; resources, F.A.; data curation, T.M.; writing—original draft preparation, T.M.; writing—review and editing, M.I.H.; visualization, F.A.; supervision, M.I.H.; project administration, D.K.Y.; funding acquisition, D.K.Y. All authors have read and agreed to the published version of the manuscript.

Funding: This work was supported by Taif University Researchers Supporting Project Number (TURSP-2020/131), Taif University, Taif, Saudi Arabia. Indian Council of Medical Research (Project No. ISRM/12(22)/2020).

Institutional Review Board Statement: Not applicable.

Informed Consent Statement: Not applicable.

Acknowledgments: This work was supported by Taif University Researchers Supporting Project Number (TURSP-2020/131), Taif University, Taif, Saudi Arabia. MIH thanks the Department of Science and Technology, Government of India for the FIST support (FIST program No. SR/FST/LSII/2020/782).

Conflicts of Interest: The authors declare no conflict of interest.

\section{References}

1. Schittek, B.; Sinnberg, T. Biological functions of casein kinase 1 isoforms and putative roles in tumorigenesis. Mol. Cancer 2014, 13, 1-14. [CrossRef]

2. Byun, K.; Kim, J.Y.; Bayarsaikhan, E.; Kim, D.; Jeong, G.-B.; Na Yun, K.; Min, H.K.; Kim, S.U.; Yoo, J.S.; Lee, B. Quantitative proteomic analysis reveals that lipopolysaccharide induces mitogen-activated protein kinase-dependent activation in human microglial cells. Electrophoresis 2012, 33, 3756-3763. [CrossRef]

3. Chun, K.; Cho, S.; Lee, J.; Seo, J.H.; Kim, K.; Lee, S. Protein kinase C- $\delta$ interacts with and phosphorylates ARD1. J. Cell. Physiol. 2021, 236, 379-391. [CrossRef]

4. Goh, Y.-M.; Cinghu, S.; Hong, E.T.H.; Lee, Y.-S.; Kim, J.-H.; Jang, J.-W.; Li, Y.-H.; Chi, X.-Z.; Lee, K.-S.; Wee, H.; et al. Src Kinase Phosphorylates RUNX3 at Tyrosine Residues and Localizes the Protein in the Cytoplasm. J. Biol. Chem. 2010, 285, 10122-10129. [CrossRef]

5. Kim, Y.-H.; Hwang, J.H.; Kim, K.-S.; Noh, J.-R.; Gang, G.-T.; Oh, W.K.; Jeong, K.-H.; Kwak, T.H.; Choi, H.-S.; Lee, I.-K.; et al. Enhanced activation of NAD(P)H. J. Hypertens. 2014, 32, 306-317. [CrossRef] [PubMed]

6. Park, J.Y.; Lee, D.-S.; Kim, C.-E.; Shin, M.-S.; Seo, C.-S.; Shin, H.-K.; Hwang, G.S.; An, J.M.; Kim, S.-N.; Kang, K.S. Effects of fermented black ginseng on wound healing mediated by angiogenesis through the mitogen-activated protein kinase pathway in human umbilical vein endothelial cells. J. Ginseng Res. 2018, 42, 524-531. [CrossRef] [PubMed]

7. Park, S.J.; Kim, H.-H.; Jung, Y.-S.; Kang, S.-J.; Cheong, H.-K.; Song, H.-K.; Lee, B.-J. Backbone resonances assignment of 19 kDa CD1 domain of human mitotic checkpoint serine/threonine-protein kinase, Bub1. Biomol. NMR Assign. 2011, 6, 109-113. [CrossRef] [PubMed]

8. Cruciat, C.-M. Casein kinase 1 and Wnt/ $\beta$-catenin signaling. Curr. Opin. Cell Biol. 2014, 31, 46-55. [CrossRef]

9. Choi, J.-S.; Bae, W.-Y.; Nam, S.; Jeong, J.-W. New Targets for Parkinson's Disease: Adhesion G Protein-Coupled Receptor B1 is Downregulated by AMP-Activated Protein Kinase Activation. OMICS A J. Integr. Biol. 2018, 22, 493-501. [CrossRef] [PubMed]

10. Lee, J.-H.; Baek, S.Y.; Jang, E.J.; Ku, S.K.; Kim, K.M.; Ki, S.H.; Kim, C.-E.; Park, K.I.; Kim, S.C.; Kim, Y.W. Oxyresveratrol ameliorates nonalcoholic fatty liver disease by regulating hepatic lipogenesis and fatty acid oxidation through liver kinase B1 and AMP-activated protein kinase. Chem. Interact. 2018, 289, 68-74. [CrossRef] [PubMed]

11. Lee, J.Y.; Choi, A.Y.; Oh, Y.T.; Choe, W.; Yeo, E.-J.; Ha, J.; Kang, I. Corrigendum to "AMP-activated protein kinase mediates T cell activation-induced expression of FasL and COX-2 via protein kinase $\mathrm{C}$ theta-dependent pathway in human Jurkat $\mathrm{T}$ leukemia cells". Cell. Signal. 2018, 52, 163. [CrossRef]

12. Lee, S.-H.; Ko, S.-C.; Kang, M.-C.; Lee, D.H.; Jeon, Y.-J. Octaphlorethol A, a marine algae product, exhibits antidiabetic effects in type 2 diabetic mice by activating AMP-activated protein kinase and upregulating the expression of glucose transporter 4 . Food Chem. Toxicol. 2016, 91, 58-64. [CrossRef]

13. Son, E.S.; Kyung, S.Y.; Lee, S.P.; Jeong, S.H.; Shin, J.Y.; Ohba, M.; Yeo, E.J.; Park, J.W. Role of protein kinase C- $\eta$ in cigarette smoke extract-induced apoptosis in MRC-5-cells. Hum. Exp. Toxicol. 2015, 34, 869-877. [CrossRef]

14. Son, K.H.; Park, C.H.; Park, K.Y.; Choi, C.H. Which Variables Should be Considered as Confounders of p38-Mitogen Activated Protein Kinase Activation Measurements? Ann. Thorac. Surg. 2016, 102, 1764-1765. [CrossRef] [PubMed] 
15. Lantermann, A.B.; Chen, D.; McCutcheon, K.; Hoffman, G.; Frias, E.; Ruddy, D.; Rakiec, D.; Korn, J.; McAllister, G.; Stegmeier, F. Inhibition of casein kinase 1 alpha prevents acquired drug resistance to Erlotinib in EGFR-mutant non-small cell lung cancer. Cancer Res. 2015, 75, 4937-4948. [CrossRef]

16. Janovská, P.; Normant, E.; Miskin, H.; Bryja, V. Targeting Casein Kinase 1 (CK1) in Hematological Cancers. Int. J. Mol. Sci. 2020, 21, 9026. [CrossRef] [PubMed]

17. Knippschild, U.; Wolff, S.; Giamas, G.; Brockschmidt, C.; Wittau, M.; Würl, P.U.; Eismann, T.; Stöter, M. The role of the casein kinase 1 (CK1) family in different signaling pathways linked to cancer development. Oncol. Res. Treat. 2005, 28, 508-514. [CrossRef] [PubMed]

18. Jiang, S.; Zhang, M.; Sun, J.; Yang, X. Casein kinase $1 \alpha$ : Biological mechanisms and theranostic potential. Cell Commun. Signal. 2018, 16, 1-24. [CrossRef]

19. Kim, H.-J.; Kim, D.Y.; Cheon, H.G. Clomiphene promotes browning of white adipocytes via casein kinase-2 inhibition. Eur. J. Pharmacol. 2019, 861, 172596. [CrossRef]

20. Tran, N.; Chun, K.-H. ROCK2-Specific Inhibitor KD025 Suppresses Adipocyte Differentiation by Inhibiting Casein Kinase 2. Molecules 2021, 26, 4747. [CrossRef] [PubMed]

21. Xu, R.-M.; Carmel, G.; Sweet, R.M.; Kuret, J.; Cheng, X. Crystal structure of casein kinase-1, a phosphate-directed protein kinase. EMBO J. 1995, 14, 1015-1023. [CrossRef] [PubMed]

22. Minzel, W.; Venkatachalam, A.; Fink, A.; Hung, E.; Brachya, G.; Burstain, I.; Shaham, M.; Rivlin, A.; Omer, I.; Zinger, A. Small molecules co-targeting CKI $\alpha$ and the transcriptional kinases CDK7/9 control AML in preclinical models. Cell 2018, 175, 171-185. e125. [CrossRef]

23. Cho, J.M.; Yang, E.H.; Quan, W.; Nam, E.H.; Cheon, H.G. Discovery of a novel fibroblast activation protein (FAP) inhibitor, BR103354, with anti-diabetic and anti-steatotic effects. Sci. Rep. 2020, 10, 1-17. [CrossRef] [PubMed]

24. Lee, S.-M.; Kim, M.-S.; Hayat, F.; Shin, D. Recent advances in the discovery of novel antiprotozoal agents. Molecules 2019, $24,3886$. [CrossRef] [PubMed]

25. Oh, M.; Ahn, J.; Lee, T.; Jang, G.; Park, C.; Yoon, Y. Drug voyager: A computational platform for exploring unintended drug action. BMC Bioinform. 2017, 18, 1-13. [CrossRef]

26. Jairajpuri, D.S.; Mohammad, T.; Adhikari, K.; Gupta, P.; Hasan, G.M.; Alajmi, M.F.; Rehman, M.T.; Hussain, A.; Hassan, M.I. Identification of sphingosine kinase-1 inhibitors from bioactive natural products targeting cancer therapy. ACS Omega 2020, 5, 14720-14729. [CrossRef]

27. Mohammad, T.; Khan, F.I.; Lobb, K.A.; Islam, A.; Ahmad, F.; Hassan, M.I. Identification and evaluation of bioactive natural products as potential inhibitors of human microtubule affinity-regulating kinase 4 (MARK4). J. Biomol. Struct. Dyn. 2019, 37, 1813-1829. [CrossRef]

28. Alam, M.; Ali, S.; Mohammad, T.; Hasan, G.M.; Yadav, D.K.; Hassan, M. B Cell Lymphoma 2: A Potential Therapeutic Target for Cancer Therapy. Int. J. Mol. Sci. 2021, 22, 10442. [CrossRef]

29. Choi, J.; Choi, K.-E.; Park, S.J.; Kim, S.Y.; Jee, J.-G. Ensemble-Based Virtual Screening Led to the Discovery of New Classes of Potent Tyrosinase Inhibitors. J. Chem. Inf. Model. 2016, 56, 354-367. [CrossRef]

30. Jang, C.; Yadav, D.K.; Subedi, L.; Venkatesan, R.; Venkanna, A.; Afzal, S.; Lee, E.; Yoo, J.; Ji, E.; Kim, S.Y.; et al. Identification of novel acetylcholinesterase inhibitors designed by pharmacophore-based virtual screening, molecular docking and bioassay. Sci. Rep. 2018, 8, 14921. [CrossRef]

31. Lee, J.H.; Cho, S.J.; Kim, M.-H. Discovery of CNS-Like D3R-Selective Antagonists Using 3D Pharmacophore Guided Virtual screening. Molecules 2018, 23, 2452. [CrossRef] [PubMed]

32. Shoichet, B.K. Virtual screening of chemical libraries. Nat. Cell Biol. 2004, 432, 862-865. [CrossRef] [PubMed]

33. Naqvi, A.A.; Mohammad, T.; Hasan, G.M.; Hassan, M. Advancements in docking and molecular dynamics simulations towards ligand-receptor interactions and structure-function relationships. Curr. Top. Med. Chem. 2018, 18, 1755-1768. [CrossRef] [PubMed]

34. Teli, M.K.; Kumar, S.; Yadav, D.K.; Kim, M.H. In silico identification of prolyl hydroxylase inhibitor by per-residue energy decomposition-based pharmacophore approach. J. Cell. Biochem. 2021, 122, 1098-1112. [CrossRef]

35. Yadav, D.K.; Kumar, S.; Choi, E.-H.; Chaudhary, S.; Kim, M.-H. Computational modeling on aquaporin-3 as skin cancer target: A virtual screening study. Front. Chem. 2020, 8, 250. [CrossRef] [PubMed]

36. Waseem, R.; Anwar, S.; Khan, S.; Shamsi, A.; Hassan, M.; Anjum, F.; Shafie, A.; Islam, A.; Yadav, D.K. MAP/Microtubule Affinity Regulating Kinase 4 Inhibitory Potential of Irisin: A New Therapeutic Strategy to Combat Cancer and Alzheimer's Disease. Int. J. Mol. Sci. 2021, 22, 10986. [CrossRef]

37. Teli, M.K.; Kumar, S.; Yadav, D.K.; Kim, M.-H. In silico identification of hydantoin derivatives: A novel natural prolyl hydroxylase inhibitor. J. Biomol. Struct. Dyn. 2021, 39, 703-717. [CrossRef] [PubMed]

38. Lipinski, C.A. Lead-and drug-like compounds: The rule-of-five revolution. Drug Discov. Today Technol. 2004, 1, 337-341. [CrossRef]

39. Baell, J.B. Feeling nature's PAINS: Natural products, natural product drugs, and pan assay interference compounds (PAINS). J. Nat. Prod. 2016, 79, 616-628. [CrossRef]

40. Lagunin, A.; Stepanchikova, A.; Filimonov, D.; Poroikov, V. PASS: Prediction of activity spectra for biologically active substances. Bioinformatics 2000, 16, 747-748. [CrossRef] 
41. Koparde, A.A.; Doijad, R.C.; Magdum, C.S. Natural products in drug discovery. In Pharmacognosy-Medicinal Plants; IntechOpen: London, UK, 2019.

42. Reddy, L.; Odhav, B.; Bhoola, K. Natural products for cancer prevention: A global perspective. Pharmacol. Ther. 2003, 99, 1-13. [CrossRef]

43. Morris, G.M.; Huey, R.; Olson, A.J. Using autodock for ligand-receptor docking. Curr. Protoc. Bioinform. 2008, 24, 8.14.11-8.14.40. [CrossRef] [PubMed]

44. Mohammad, T.; Mathur, Y.; Hassan, M.I. InstaDock: A single-click graphical user interface for molecular docking-based virtual high-throughput screening. Brief Bioinform. 2021, 22, bbaa279. [CrossRef]

45. DeLano, W.L. Pymol: An open-source molecular graphics tool. CCP4 Newsl. Protein Crystallogr. 2002, 40, 82-92.

46. Dassault Systemes BIOVIA. Discovery Studio, Accelrys [2.1]; Dassault Systemes BIOVIA: San Diego, CA, USA, 2008.

47. Mohanraj, K.; Karthikeyan, B.S.; Vivek-Ananth, R.; Chand, R.B.; Aparna, S.; Mangalapandi, P.; Samal, A. IMPPAT: A curated database of I ndian M edicinal P lants, P hytochemistry A nd T herapeutics. Sci. Rep. 2018, 8, 1-17.

48. Daina, A.; Michielin, O.; Zoete, V. SwissADME: A free web tool to evaluate pharmacokinetics, drug-likeness and medicinal chemistry friendliness of small molecules. Sci. Rep. 2017, 7, 1-13. [CrossRef]

49. Pires, D.E.; Blundell, T.L.; Ascher, D.B. pkCSM: Predicting small-molecule pharmacokinetic and toxicity properties using graph-based signatures. J. Med. Chem. 2015, 58, 4066-4072. [CrossRef]

50. Rai, R.; Dutta, R.K.; Singh, S.; Yadav, D.K.; Kumari, S.; Singh, H.; Gupta, R.D.; Pratap, R. Synthesis, biological evaluation and molecular docking study of 1-amino-2-aroylnaphthalenes against prostate cancer. Bioorganic Med. Chem. Lett. 2018, 28, 1574-1580. [CrossRef] [PubMed]

51. Poornima, B.; Siva, B.; Venkanna, A.; Shankaraiah, G.; Jain, N.; Yadav, D.K.; Misra, S.; Babu, K.S. Novel Gomisin B analogues as potential cytotoxic agents: Design, synthesis, biological evaluation and docking studies. Eur. J. Med. Chem. 2017, 139, 441-453. [CrossRef] [PubMed]

52. Amir, M.; Mohammad, T.; Prasad, K.; Hasan, G.M.; Kumar, V.; Dohare, R.; Islam, A.; Ahmad, F.; Imtaiyaz Hassan, M. Virtual high-throughput screening of natural compounds in-search of potential inhibitors for protection of telomeres 1 (POT1). J. Biomol. Struct. Dyn. 2020, 38, 4625-4634. [CrossRef]

53. Mohammad, T.; Siddiqui, S.; Shamsi, A.; Alajmi, M.F.; Hussain, A.; Islam, A.; Ahmad, F.; Hassan, M. Virtual screening approach to identify high-affinity inhibitors of serum and glucocorticoid-regulated kinase 1 among bioactive natural products: Combined molecular docking and simulation studies. Molecules 2020, 25, 823. [CrossRef]

54. Sharma, V.; Jaiswal, P.K.; Kumar, S.; Mathur, M.; Swami, A.K.; Yadav, D.K.; Chaudhary, S. Discovery of Aporphine Analogues as Potential Antiplatelet and Antioxidant Agents: Design, Synthesis, Structure-Activity Relationships, Biological Evaluations, and in silico Molecular Docking Studies. ChemMedChem 2018, 13, 1817-1832. [CrossRef]

55. Gimeno, A.; Montes, M.J.O.; Tomás-Hernández, S.; Cereto-Massagué, A.; Beltrán-Debón, R.; Mulero, M.; Pujadas, G.; GarciaVallvé, S. The Light and Dark Sides of Virtual Screening: What Is There to Know? Int. J. Mol. Sci. 2019, 20, 1375. [CrossRef] [PubMed]

56. Tiwari, M.K.; Coghi, P.; Agrawal, P.; Shyamlal, B.R.K.; Yang, L.J.; Yadav, L.; Peng, Y.; Sharma, R.; Yadav, D.K.; Sahal, D. Design, Synthesis, Structure-Activity Relationship and Docking Studies of Novel Functionalized Arylvinyl-1, 2, 4-Trioxanes as Potent Antiplasmodial as well as Anticancer Agents. ChemMedChem 2020, 15, 1216-1228. [CrossRef]

57. Ahmed, N.; Anwar, S.; Thet Htar, T. Docking based 3D-QSAR study of tricyclic guanidine analogues of batzelladine K as anti-malarial agents. Front. Chem. 2017, 5, 36. [CrossRef]

58. Kalani, K.; Yadav, D.K.; Alam, S.; Khan, F.; Kashyap, M.P.; Srivastava, S.K.; Pant, A.B. In-silico Studies and Wet-Lab Validation of Camptothecin Derivatives for Anti-Cancer Activity Against Liver (HepG2) and Lung (A549) Cancer Cell Lines. Curr. Top. Med. Chem. 2021, 21, 1-12. [CrossRef]

59. Kim, H.-H.; Hyun, J.-S.; Choi, J.; Choi, K.-E.; Jee, J.-G.; Park, S.J. Structural ensemble-based docking simulation and biophysical studies discovered new inhibitors of Hsp90 N-terminal domain. Sci. Rep. 2018, 8, 1-13.

60. Guleria, V.; Pal, T.; Sharma, B.; Chauhan, S.; Jaiswal, V. Pharmacokinetic and molecular docking studies to design antimalarial compounds targeting Actin I. Int. J. Health Sci. 2021, 15, 4-13.

61. Yadav, D.K.; Kumar, S.; Teli, M.K.; Kim, M.H. Ligand-based pharmacophore modeling and docking studies on vitamin D receptor inhibitors. J. Cell. Biochem. 2020, 121, 3570-3583. [CrossRef]

62. Hirte, M.; Meese, N.; Mertz, M.; Fuchs, M.; Brück, T.B. Insights into the bifunctional aphidicolan-16-ß3-ol synthase through rapid biomolecular modeling approaches. Front. Chem. 2018, 6, 101. [CrossRef] [PubMed]

63. Arunkumar, R.; Sharmila, G.; Elumalai, P.; Senthilkumar, K.; Banudevi, S.; Gunadharini, D.; Benson, C.; Daisy, P.; Arunakaran, J. Effect of diallyl disulfide on insulin-like growth factor signaling molecules involved in cell survival and proliferation of human prostate cancer cells in vitro and in silico approach through docking analysis. Phytomedicine 2012, 19, 912-923. [CrossRef] [PubMed]

64. Pearlman, D.A.; Case, D.A.; Caldwell, J.W.; Ross, W.S.; Cheatham III, T.E.; DeBolt, S.; Ferguson, D.; Seibel, G.; Kollman, P. AMBER, a package of computer programs for applying molecular mechanics, normal mode analysis, molecular dynamics and free energy calculations to simulate the structural and energetic properties of molecules. Comput. Phys. Commun. 1995, 91, 1-41. [CrossRef] 
65. He, X.; Liu, S.; Lee, T.-S.; Ji, B.; Man, V.H.; York, D.M.; Wang, J. Fast, accurate, and reliable protocols for routine calculations of protein-ligand binding affinities in drug design projects using AMBER GPU-TI with ff14SB/GAFF. ACS Omega 2020, 5, 4611-4619. [CrossRef]

66. Wang, J.; Wolf, R.M.; Caldwell, J.W.; Kollman, P.A.; Case, D.A. Development and testing of a general amber force field. J. Comput. Chem. 2004, 25, 1157-1174. [CrossRef] [PubMed]

67. Jakalian, A.; Bush, B.L.; Jack, D.B.; Bayly, C.I. Fast, efficient generation of high-quality atomic charges. AM1-BCC model: I. Method. J. Comput. Chem. 2000, 21, 132-146. [CrossRef]

68. Mark, P.; Nilsson, L. Structure and dynamics of the TIP3P, SPC, and SPC/E water models at 298 K. J. Phys. Chem. A 2001, 105, 9954-9960. [CrossRef]

69. Roe, D.R.; Cheatham III, T.E. PTRAJ and CPPTRAJ: Software for processing and analysis of molecular dynamics trajectory data. J. Chem. Theory Comput. 2013, 9, 3084-3095. [CrossRef]

70. Fataftah, H.; Karain, W. Detecting protein atom correlations using correlation of probability of recurrence. Proteins: Struct. Funct. Bioinform. 2014, 82, 2180-2189. [CrossRef]

71. David, C.C.; Jacobs, D.J. Principal component analysis: A method for determining the essential dynamics of proteins. In Protein Dynamics; Humana Press: Totowa, NJ, USA, 2014; pp. 193-226.

72. Amir, M.; Mohammad, T.; Kumar, V.; AlAjmi, M.; Rehman, M.T.; Hussain, A.; Alam, P.; Dohare, R.; Islam, A.; Ahmad, F. Structural analysis and conformational dynamics of STN1 gene mutations involved in coat plus syndrome. Front. Mol. Biosci. $2019,6,41$. [CrossRef]

73. Jairajpuri, D.S.; Hussain, A.; Nasreen, K.; Mohammad, T.; Anjum, F.; Rehman, T.; Hasan, G.M.; Alajmi, M.F.; Hassan, I. Identification of natural compounds as potent inhibitors of SARS-CoV-2 main protease using combined docking and molecular dynamics simulations. Saudi J. Biol. Sci. 2021, 28, 2423-2431. [CrossRef]

74. Papaleo, E.; Mereghetti, P.; Fantucci, P.; Grandori, R.; De Gioia, L. Free-energy landscape, principal component analysis, and structural clustering to identify representative conformations from molecular dynamics simulations: The myoglobin case. J. Mol. Graph. Model. 2009, 27, 889-899. [CrossRef] [PubMed]

75. Genheden, S.; Ryde, U. The MM/PBSA and MM/GBSA methods to estimate ligand-binding affinities. Expert Opin. Drug Discov. 2015, 10, 449-461. [CrossRef] [PubMed]

76. Miller, B.R., III; McGee, T.D., Jr; Swails, J.M.; Homeyer, N.; Gohlke, H.; Roitberg, A.E. MMPBSA. py: An efficient program for end-state free energy calculations. J. Chem. Theory Comput. 2012, 8, 3314-3321. [CrossRef]

77. Razia, S.; Park, H.; Shin, E.; Shim, K.-S.; Cho, E.; Kim, S.-Y. Effects of Aloe vera Flower Extract and Its Active Constituent Isoorientin on Skin Moisturization via Regulating Involucrin Expression: In Vitro and Molecular Docking Studies. Molecules 2021, 26, 2626. [CrossRef]

78. Yadav, D.K.; Kumar, S.; Saloni, S.; Singh, H.; Kim, M.-H.; Sharma, P.; Misra, S.; Khan, F. Molecular docking, QSAR and ADMET studies of withanolide analogs against breast cancer. Drug Des. Dev. Ther. 2017, ume 11, 1859-1870. [CrossRef]

79. Anjum, F.; Mohammad, T.; Almalki, A.A.; Akhtar, O.; Abdullaev, B.; Hassan, M.I. Phytoconstituents and Medicinal Plants for Anticancer Drug Discovery: Computational Identification of Potent Inhibitors of PIM1 Kinase. OMICS A J. Integr. Biol. 2021, 25, 580-590. [CrossRef] [PubMed]

80. Gadhe, C.G.; Balupuri, A.; Cho, S.J. In silicocharacterization of binding mode of CCR8 inhibitor: Homology modeling, docking and membrane based MD simulation study. J. Biomol. Struct. Dyn. 2015, 33, 2491-2510. [CrossRef]

81. Lee, K.-Y.; Choi, H.-S.; Choi, H.-S.; Chung, K.Y.; Lee, B.-J.; Maeng, H.-J.; Seo, M.-D. Quercetin Directly Interacts with Vitamin D Receptor (VDR): Structural Implication of VDR Activation by Quercetin. Biomol. Ther. 2016, 24, 191-198. [CrossRef]

82. Rocha, S.F.D.S.; Olanda, C.G.; Fokoue, H.H.; Sant'Anna, C.M. Virtual Screening Techniques in Drug Discovery: Review and Recent Applications. Curr. Top. Med. Chem. 2019, 19, 1751-1767. [CrossRef]

83. Maia, E.H.B.; Assis, L.C.; de Oliveira, T.A.; Da Silva, A.M.; Taranto, A.G. Structure-Based Virtual Screening: From Classical to Artificial Intelligence. Front. Chem. 2020, 8. [CrossRef]

84. Yadav, D.K.; Kumar, S.; Choi, E.-H.; Sharma, P.; Misra, S.; Kim, M.-H. Insight Into the Molecular Dynamic Simulation Studies of Reactive Oxygen Species in Native Skin Membrane. Front. Pharmacol. 2018, 9, 644. [CrossRef] [PubMed]

85. Lobanov, M.Y.; Bogatyreva, N.; Galzitskaya, O. Radius of gyration as an indicator of protein structure compactness. Mol. Biol. 2008, 42, 623-628. [CrossRef]

86. Hubbard, R.E.; Haider, M.K. Hydrogen bonds in proteins: Role and strength. eLS 2010. [CrossRef]

87. Xie, M.; Schowen, R.L. Secondary structure and protein deamidation. J. Pharm. Sci. 1999, 88, 8-13. [CrossRef] [PubMed]

88. Jo, H.; Choi, M.; Sim, J.; Viji, M.; Li, S.; Lee, Y.H.; Kim, Y.; Seo, S.-Y.; Zhou, Y.; Lee, K.; et al. Synthesis and biological evaluation of caffeic acid derivatives as potent inhibitors of $\alpha$-MSH-stimulated melanogenesis. Bioorganic Med. Chem. Lett. 2017, 27, $3374-3377$. [CrossRef] [PubMed]

89. Kim, H.-H.; Park, S.J.; Han, J.-H.; Pathak, C.; Cheong, H.-K.; Lee, B.-J. Structural insight into the interaction between the Hox and HMGB1 and understanding of the HMGB1-enhancing effect of Hox-DNA binding. Biochim. Biophys. Acta (BBA)-Proteins Proteom. 2015, 1854, 449-459. [CrossRef] [PubMed]

90. Park, S.J.; Son, W.S.; Lee, B.-J. Structural Analysis of Hypothetical Proteins from Helicobacter pylori: An Approach to Estimate Functions of Unknown or Hypothetical Proteins. Int. J. Mol. Sci. 2012, 13, 7109-7137. [CrossRef] [PubMed] 
91. Grimaldo, M.; Roosen-Runge, F.; Zhang, F.; Schreiber, F.; Seydel, T. Dynamics of proteins in solution. Q. Rev. Biophys. 2019, 52, 52. [CrossRef]

92. Mishra, S.K.; Jernigan, R.L. Protein dynamic communities from elastic network models align closely to the communities defined by molecular dynamics. PLoS ONE 2018, 13, e0199225. [CrossRef]

93. Lever, J.; Krzywinski, M.; Altman, N. Points of significance: Principal component analysis. Nat. Methods 2017, 14, 641-643. [CrossRef]

94. Fatima, S.; Mohammad, T.; Jairajpuri, D.S.; Rehman, M.T.; Hussain, A.; Samim, M.; Ahmad, F.J.; Alajmi, M.F.; Hassan, M.I. Identification and evaluation of glutathione conjugate gamma-l-glutamyl-l-cysteine for improved drug delivery to the brain. J. Biomol. Struct. Dyn. 2020, 38, 3610-3620. [CrossRef] [PubMed]

95. Ali, S.; Khan, F.I.; Mohammad, T.; Lan, D.; Hassan, M.; Wang, Y. Identification and evaluation of inhibitors of lipase from Malassezia restricta using virtual high-throughput screening and molecular dynamics studies. Int. J. Mol. Sci. 2019, 20, 884. [CrossRef]

96. Dahiya, R.; Mohammad, T.; Roy, S.; Anwar, S.; Gupta, P.; Haque, A.; Khan, P.; Kazim, S.N.; Islam, A.; Ahmad, F. Investigation of inhibitory potential of quercetin to the pyruvate dehydrogenase kinase 3: Towards implications in anticancer therapy. Int. J. Biol. Macromol. 2019, 136, 1076-1085. [CrossRef] [PubMed]

97. Khan, A.; Mohammad, T.; Shamsi, A.; Hussain, A.; Alajmi, M.F.; Husain, S.A.; Iqbal, M.A.; Hassan, M.I. Identification of plant-based hexokinase 2 inhibitors: Combined molecular docking and dynamics simulation studies. J. Biomol. Struct. Dyn. 2021, 1-13. [CrossRef]

98. Limongelli, V. Ligand binding free energy and kinetics calculation in 2020. Wiley Interdiscip. Rev. Comput. Mol. Sci. 2020, 10, e1455. [CrossRef] 